\title{
PBL Implementation of Kathmandu University Curriculum - Is It Quo Vadis?
}

\author{
Hemang Dixit,' Sujan Vaidya, ${ }^{1}$ Binita Pradhan' \\ 'Department of Medical Education, Kathmandu Medical College, Sinamangal, Kathmandu, Nepal.
}

\begin{abstract}
The history of the implementation of PBL which started in 1978 is long and there have been many ups and downs in the process of getting it to work. Of course there are many reasons for this, starting with the fact that basically it is a method of learning of medicine that is being tried out in various parts of the world. What is envisaged by KU is a hybrid form of the process to be implemented for the MBBS course that KUSMS conducts at its campus at Chaukot, Kavre and at its seven affiliated medical colleges. Various points regarding this are discussed in this article. The information provided in the MBBS curriculum of KU was analysed and comments made there on. The syllabi of IoM, BPKIHS and PAHS were also referred to, to note the existing differences.
\end{abstract}

Keywords: curriculum; medical educaiton; problem based learning; medical education.

\section{INTRODUCTION}

The curriculum of the MBBS course at the Institute of Medicine (loM) was based on the research findings of studies done in four districts of Nepal. The course was organ system based with integrated teaching and was community oriented. Problem Based Learning (PBL) was introduced into Nepal at the time that the loM started this medical course in $1978 .{ }^{1}$ Pant DS however states that it was twenty years later in 1998 that PBL was formally introduced into the program. After this, PBL was introduced in the MBBS course at the BP Koirala Institute of Health Sciences (BPKIHS) at Dharan in $1999 .{ }^{2}$ In 2001, the Kathmandu University School of Medical Sciences (KUSMS) with the support of Harvard University started their MBBS course. ${ }^{3}$ After this it was the Patan Academy of Health Sciences (PAHS) that started the MBBS course. As from 2011 all the seven colleges affiliated to Kathmandu University (KU) also partly switched their teaching / learning activities to this form as per the Pre Clinical Sciences revised version of 2011 MBBS curriculum of KUSMS. ${ }^{4}$ Such is the situation now and what is being practiced in Nepal is a hybrid form of PBL. In fact no institution in Nepal has totally replaced or changed their methods of teaching to this form of medical education. The organ - system approach and community orientation are existing at varying degrees in the medical courses conducted by the four universities / deemed universities of Nepal.

Prof. Jayawickramarajah, during the course of a workshop held at KMC in 2013 spoke about and highlighted the concept of the amalgamation of the medical training between the Basic Sciences period and the clinical training by showing a square with a sloping line going from top of the left corner to the bottom right corner. Triangle $B$ on left signified and showed the maximum input of basic sciences in the first two years being gradually replaced by clinical input $C$ in the following two and half years.

Correspondence: Dr. Hemang Dixit, Medical Education Department, Kathmandu Medical College, Sinamangal, Kathmandu, Nepal. Email: h2dixit@gmail.com, Phone: +977-01-4413460. 


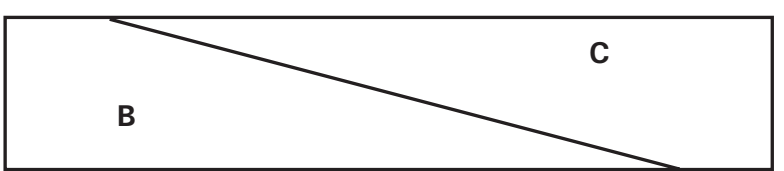

Now looking at the KU curriculum with all this in mind one comes across the under mentioned facts regarding introduction to clinical medicine (ICM).

\begin{tabular}{|c|c|c|c|}
\hline System (Section) & $\begin{array}{l}\text { ICM } \\
\text { Theory }\end{array}$ & $\begin{array}{l}\text { ICM } \\
\text { Practical }\end{array}$ & PBL \\
\hline $\begin{array}{l}\text { Basic Concepts (5 } \\
\text { weeks) }\end{array}$ & 3 & 4 & 26 \\
\hline Genetics (1 week) & 1 & 2 & 12 \\
\hline Immunology (2 weeks) & 1 & - & - \\
\hline $\begin{array}{l}\text { Autonomic N.S. (1 } \\
\text { week) }\end{array}$ & - & - & - \\
\hline $\begin{array}{l}\text { Integumentary (1 } \\
\text { week) }\end{array}$ & 1 & 2 & \\
\hline $\begin{array}{l}\text { Musculo-Skeletal (6 } \\
\text { wks) }\end{array}$ & 3 & 4 & 62 \\
\hline Hours & $9+$ & $12=21$ & 100 \\
\hline
\end{tabular}

\begin{tabular}{|llll|}
\hline \multicolumn{4}{l}{ Semester II - Self Study to be $\mathbf{1 6 3}$ hours } \\
\hline System & ICM & ICM & \\
& Theory & Practical & PBL \\
Haemopoetic (4 weeks) & 2 & 4 & 38 \\
Cardio-Vascular (6 wks) & 2 & 4 & 38 \\
Respiratory (6 weeks) & 2 & 4 & 38 \\
Hours & $6+$ & $12=18$ & 114 \\
\hline
\end{tabular}

\begin{tabular}{|c|c|c|c|}
\hline \multicolumn{4}{|c|}{ Semester III - Self Study to be 98 hours } \\
\hline \multirow{2}{*}{ System } & ICM & ICM & \multirow{2}{*}{ PBL } \\
\hline & Theory & Practical & \\
\hline $\begin{array}{l}\text { Gastro-intestinal (6 } \\
\text { wks) }\end{array}$ & 2 & 4 & 38 \\
\hline $\begin{array}{l}\text { Hepato-biliary ( } 2 \\
\text { weeks) }\end{array}$ & 2 & 2 & 14 \\
\hline Renal (4 weeks) & 2 & 2 & 38 \\
\hline $\begin{array}{l}\text { Endocrine \& } \\
\text { Metabolic (4 wks) }\end{array}$ & 3 & 4 & 38 \\
\hline Hours & $9+$ & $12=21$ & 128 \\
\hline
\end{tabular}

\begin{tabular}{|llll|}
\hline \multicolumn{4}{|l|}{ Semester IV - Self Study to be $\mathbf{9 8}$ hours } \\
\hline $\begin{array}{l}\text { ICM } \\
\text { System }\end{array}$ & $\begin{array}{l}\text { ICM } \\
\text { Pheory }\end{array}$ & Practical & PBL \\
$\begin{array}{l}\text { Reproductive ( } 7 \\
\text { weeks) }\end{array}$ & 4 & 6 & 50 \\
$\begin{array}{l}\text { Central Nervous } \\
\left(\begin{array}{l}9 \text { weeks) } \\
\text { Hours }\end{array}\right.\end{array}$ & 4 & 6 & 62 \\
\hline
\end{tabular}

First semester: Students should know about: i). Medical Ethics. ii). Art of History Taking. iii) Clinical Examination. The first year students are made aware about medical history and ethics from down the ages and are introduced early on to clinical methods to develop their expertise which in turn is felt to be very much more rational and helpful in developing their clinical acumen.

Second semester: Be proficient in examination of the Respiratory and Cardiovascular Systems.

Third semester: Should know themes and topics of Gastrointestinal, Hepatobiliary, Renal, Metabolic and Endocrine System.

Fourth semester: Should know themes and topics of Reproductive and Central Nervous Systems plus also about the special senses.

\section{Background}

Barrows \& Tamblyn ${ }^{5}$ in their book state:

“... problem based learning around patient problems inevitably leads to clinical learning and not to effective basic sciences learning. The hypotheses developed depend on the educational objectives."

Going through the revised Basic Sciences Syllabus of 2008 one finds that the time break up for Introduction to Clinical Medicine (Theory \& Practical) and for PBL is as in (Table 1).

Of the grand total of 2650 hours of the Basic Sciences portion of course done during the first two years, 522 hours have been allotted for self study by the students. The allotted hours for the different subjects are as shown in (Table 2).

\begin{tabular}{|llll|}
\hline \multicolumn{3}{|l|}{ Table 2. Hours allocation. } & \\
\hline Subject & $\begin{array}{l}\text { Hours } \\
\text { Allocated } \\
\text { by KU }\end{array}$ & Subject & $\begin{array}{l}\text { Hours } \\
\text { allocated } \\
\text { by KU }\end{array}$ \\
$\begin{array}{l}\text { Anatomy } \\
\text { Com. }\end{array}$ & 313 & Biochemistry & 187 \\
Medicine & 287 & Microbiology & 171 \\
$\begin{array}{l}\text { Pathology } \\
\text { Physiology }\end{array}$ & 207 & Pharmacology & 211 \\
\hline
\end{tabular}

Though 214 hours are being allocated by KU for PBL in the first year and 240 in the second, KMC is so far utilizing only 96 and 90 hours respectively for 14 and 11 cases in the first and second years as reported in a recent article. This is shown in (Table 3). 
Dixit et al. PBL Implementation Of Ku Curriculum - Is It Quo Vadis?

\begin{tabular}{|lll|}
\hline \multicolumn{3}{|l|}{ Table 3. Hours Allocation for PBL. } \\
\hline Year & KU Allocation & In Practice \\
$1^{\text {st }}$ Year & 214 & 96 for 14 cases \\
$2^{\text {nd }}$ Year & 240 & 90 for 11 cases \\
\hline
\end{tabular}

We are therefore not overburdening the students and even of allotted time half of the period is being utilised by the students for self directed learning (SDL). What has actually happened is that whilst PBL seems to have been introduced, the corresponding deletion of curricular matter which may be over stressed or redundant has to be looked at. Even then the eternal feedback from the students is that they are overburdened as they may be utilising the time for unrelated activities.

The introduction to clinical medicine (ICM) theory and practical comes to 28 and 49 hours over the course of the first two years and is minimal. It is in conformity with the World Federation of Medical Education (WFME) and International Institute of Medical Education (IIME) recommendations which call for early exposure of the students to clinical medicine so that they are aware of the relevance of their learning. There has to be some more stress on the community aspects of all problems and more liaisons with the Community Medicine Department.

Just as one was not and is not expected to see each and every illness or condition during the course of one's medical study and training, one cannot be expected to have discussed all the common sixty-six clinical problems, (35 in first year and 31 in second) that are listed in Annex I. What must however be remembered is the fact that there may be some other conditions which the students come across which may be more appropriate for detailed work-out and will contribute to their learning process.

One of the problems of medical education these days is the difficulty of giving "hands on" experience to the students. This is partly due to the fact that patient numbers are limited and the student numbers are large. This state of affairs is one of the difficulties when implementing PBL. Barrows \& Tamblyn in their book, printed in 1980 and referred to already have given suggestions to get around this by:

1. Written case histories.

2. Living patients / Simulated patients.

The student then has other options such as:

a. Patient Management Problem (PMP).

b. Sequential Management Problem (SMP)

c. Portable Patient Problem Pack (P4)

d. Computer Format
The authors then advocated enhancing the value of these formats by integrating audio-visual media and by use of skill laboratories. We in Nepal now have to solve these problems, which had been envisaged by the authors over 43 years ago. It is interesting to note that the then feeling of the authors was that relating to expense, complexity and difficulty in use then due to the fixed and stationery state of computers. Such feelings now seem as archaic as the world has changed almost upside down over this time period and the storage, complexity, utility and mobility of the computer in its varied forms are plus points now.

We at KMC have utilised the services of a Down's Syndrome case and a COPD patients in PBL sessions but there is difficulty in much involvement as the patients seem overawed seeing the number of students.

The gist of Barrow's learning model of PBL has been stated as:

1. Student Centered Learning

2. Small (6-10) Student Group Learning

3. Guidance by Tutor / Facilitator

4. Problem is the focus for the basis of learning

5. Problem is the medium for problem solving and to stimulate cognitive process.

6. Further knowledge acquisition by self directed learning (SDL).

The PBL scenario around the world is that there has been and there still is a lot of variation in the application of $\mathrm{PBL}$. One of the authors recollect that around 30 years ago, a biochemistry faculty member from Newcastle Medical College in Australia who was then visiting the Institute of Medicine, then remarked, "We are very radical in Newcastle. We have no official lectures in the medical course." Such is the situation in many medical colleges in the world where PBL has been implemented in the medical course.

In some other medical schools / colleges the practice is to have PBL sessions and the practice is not to cover the subject matter discussed in these sessions during the course of the regular classes. On the other hand there are other institutions which after the PBL sessions have in addition other lectures in those areas where the student feedback is that they have difficulty in comprehension.

In many medical colleges the practice is what we have been doing at KMC viz. a number of PBL sessions and regular classes in the first and second years. During the first year of implementation we had in the regular 
Dixit et al. PBL Implementation Of Ku Curriculum - Is It Quo Vadis?

classes left out some of the topics covered in the PBL sessions. There was however an outcry from the students and so we reverted back to completing the traditional teaching also.

In the Hull York Medical School (HYMS) where in addition to the PBL sessions the traditional classes are held, the students felt that PBL facilitates the delivery of an integrated curriculum. Basic and clinical sciences can be learnt together and social-economic aspects of health can also be considered in the light of their influence. ${ }^{6}$

The question often asked is regarding the number of cases that could / should be covered to attain the objectives of the program. There is a lot of variation between medical schools that have switched over completely to PBL and those which have partially done so.

x. The Medical School of the University of Queensland undergo five-hours of tutorials per week for 33 weeks during the course of its first year. ${ }^{7}$

y. First year students at Newcastle in Australia are introduced to a range of disease aetiologies, the organ systems and problems affecting individuals from birth to old age. During the next phase, totalling 36 weeks, the working problems are organised into organ systems: gastrointestinal, renal/urinary, cardiovascular, respiratory, neurology, psychiatry, haematology and endocrinology. The problems are selected, taking into consideration community importance in terms of morbidity, mortality and suitability at illustrating important basic and clinical mechanisms. ${ }^{8}$

z. An article on the implementation of PBL in three different medical schools, representing widely differing geographical regions around the world. ${ }^{9}$ The problems were taken up and tackled at different stages of the course as stated viz.

1. First stage when the stress was on basic concepts and principles.

2. Second stage when the problems were around the organ systems and

3. Third stage when the involvement was multisystem and more clinical.

The numbers involved and the time duration taken was as shown below:

\begin{tabular}{|c|c|c|}
\hline $\begin{array}{c}\text { Medical } \\
\text { School }\end{array}$ & $\begin{array}{c}\text { Number of } \\
\text { Problems }\end{array}$ & $\begin{array}{c}\text { Time duration } \\
\text { (Weeks) }\end{array}$ \\
\hline $\mathrm{A}^{*}$ & 88 & 87 \\
$\mathrm{~B}^{*}$ & 83 & 83 \\
$\mathrm{C}^{*}$ & 114 & 67 \\
\hline
\end{tabular}

\section{DISCUSSION}

The implementation of PBL has had a number of plus and minus points in the process. Whilst innovative methods may be a plus factor, the fact is that some senior faculty members have misgivings and are not very keen to change their methods of imparting knowledge. However in KMC many young faculty members had been involved in introductory PBL exercises in the past and are quite comfortable in the new situation. To get the students to learn in such a situation, one has literally to say, "Seek and ye shall find"!

Whilst many medical schools in the Western or developed world take graduates or more mature, motivated students into their medical courses of study ours are just out of Higher Secondary Schools and of varying capabilities. Whilst Medical Informatics is included in the $\mathrm{KU}$ curriculum it needs to be emphasized more. Now a day's however, though laptops and internet facilities are quite common, our present intakes of students are not all of the same capabilities. Whilst we may encourage group study and self directed learning our sources of information and knowledge, whether printed, visual or aural are still minimal. In such a situation it is necessary not only to have lectures to supplement and reinforce necessary and required information again and again.

Newly qualified doctors, just after their internships and who are preparing for the post graduate entrance examinations are ideal facilitators or tutors for active roles in imparting information and knowledge about PBL to first and second year MBBS students. They are more approachable, being almost like peers. The disadvantage with such facilitators is that just as they settle down to the environment of PBL sessions, they pass their entrance examinations and are ready to depart. The turnover of such personnel is thus rather high.

\section{CONCLUSIONS}

It was the Nepal Medical Council (NMC) which prodded $\mathrm{KU}$ towards a uniform implementation of their MBBS course curriculum both at KUSMS and the seven affiliated colleges that led to the introduction of PBL in 2011. It is as a result of this that the teaching/ learning process and the examination system has been changed or is in the process of being so. What must 
be remembered is that the older medical academic institutions like IOM and BPKIHS have revised their curriculum over the years. As far as $\mathrm{KU}$ is concerned the same has not been done to the same extent. What is of utmost necessity is that the KU curriculum needs to be tailored to the PBL concept much more than what exists at present. Because it is now only two years since that decision was taken, the implementation so far is almost restricted to the preclinical years only. The hurdle of PBL implementation in the two and half years of the clinical years is still to be confronted.

$\mathrm{KU}$ has been conscious of the need to have expertise for the implementation of PBL in all its affiliated colleges. It was with this objective in mind that $\mathrm{KU}$ arranged at the very outset some input from a medical institute of Vienna in Austria to conduct a workshop at Chaukot in Dhulikhel in 2011. A preliminary meeting with principals of medical colleges and PBL co-ordinators was held in January 2013. The feeling at that time was that in order to improve PBL strategy the whole curriculum has to be looked at for organ systems based specific learning objective in an integrated model, instead of traditional curriculum subject based specific course contents. Subsequently a five day workshop from $22^{\text {nd }}-26^{\text {th }}$ February 2013 was held at the Nepal Medical College, Kathmandu at which representatives of all KU affiliated medical colleges attended. ${ }^{10}$ About six to eight months later Prof. Dr. P.T. Jayawickramarajah from Sri Lanka and Prof. Dr. S.B. Rizyal from Nepal conducted a 2-3 days workshop on PBL at each of the seven KU affiliated medical colleges during February/December 2013. Another workshop is planned to be held at $\mathrm{KU}$ for faculty of the different colleges in 2014. The intention is to revise the basic sciences curriculum and streamline the process of ICM and PBL implementation in the MBBS course.

An account of the integration of PBL at KMC has been reported recently in the Journal of Kathmandu Medical College. It reflected somewhat on the student's perspective to PBL. Their feelings were positive but they felt that there were not enough sessions to cover the system blocks, aims and objectives in the course curriculum are not clear, topics covered in the sessions of PBL should be covered in the lecture hours also and that a meeting among the facilitators should include a student representative too and be held periodically. ${ }^{11}$ We in KMC are presently in a unique situation.

KU's current policy so far, appears to be to introduce $\mathrm{PBL}$ in the first two years. If this deduction, conclusion is correct, it is akin to 'Neither goose nor gander' or as we Nepalis generally remark, "Na hanse ko chaal na kukhura ko chaal". What the future holds for the rest of the training is still to be seen. KU should immediately give a time frame as to when it intends to start PBL in the clinical years and when this is expected to be completed.

What is necessary for $\mathrm{KU}$ and Nepal Medical Council (NMC) to work out and quantify the various grades of faculty and non-faculty tutors or facilitators necessary for medical colleges conducting the teaching / learning of the MBBS course by way of the PBL methods.

Last but not least are the methods of assessment and evaluation that needs to be done. Are we as teachers really reaching out and helping those students who have come to us to imbibe knowledge which we profess to give out? With the large numbers of student intakes per year, one wonders as to whether faculty members are really in a position to correctly assess the student who is confronting him or her at the time of the final examination. There is already consensus between the KUSMS and the affiliated medical colleges that the whole assessment system has to be reviewed to match with the problem based learning.

A relatively recent paper about $\mathrm{PBL}$ states, 'PBL in the medical school no longer has a single universal definition. As a result, a great deal of misunderstanding surrounds the interpretation of this educational philosophy. ${ }^{12}$ Another problem with PBL is the word 'problem'. Problems have solutions, and, to many, PBL is actually problem solving (sometimes referred to as case based learning). It is stated that Barrows didn't have a problem with different types of PBL, but when they become teacher centered more than student centered, it's not really PBL anymore - it's problem solving (9). As KUSMS is responsible for the implementation of the curriculum the primary task now is an updating and revision of the same so that it put into effective use in all the institutions affiliated to $\mathrm{KU}$ for the conduction of the MBBS course.

In conclusion one may refer to Savery JR who feels that "students are responsible for the contents in the curriculum that they have 'covered' through engagement with problems. They need to be able to recognise and articulate what they know and what they have learned". ${ }^{13}$

\section{ACKNOWLEDGEMENTS}

We would like to thank Prof. Dr. Ramesh Adhikari, Mr. Eurek Ranjit and Mr. Sanjaya Mani Dixit for having kindly gone over this article and made suggestions for 
improvements. Thanks also to Mr. Nirmal Bista and Ms. Bindu Phuyal for their help in the preparation of this manuscript.

Annex I - Commom Clinical Problems Stated in KU Curriculum

\begin{tabular}{|ll|}
\hline SEMESTER I & \\
\hline Genetics & Autonomic Nervous System \\
Cerebral Palsy & Shock \\
Down's Syndrome & Colic \\
Intra-Uterine Growth & Organophosphorous \\
Retardation & Poisoning \\
Lactose Intolerance & Mushroom Poisoning \\
Prematurity & Myasthenia Gravis \\
\hline SEMESTER I & \\
\hline Integumentary System & Muscular Skeletal System \\
Burn & Tetanus \\
Scabies & Hemiplegic \\
Dermatitis & Osteomyelitis \\
Leprosy & Varicose Veins \\
Malignancies & Arthritis \\
& Injuries \\
\hline
\end{tabular}

\begin{tabular}{|ll|}
\hline SEMESTER II & \\
\hline $\begin{array}{l}\text { Haemopoetic } \\
\text { System }\end{array}$ & Respiratory System \\
Haemorrhage & Acute Respiratory Infection \\
Anaemia & Tuberculosis \\
Leishmaniasis & Bronchial Asthma \\
Filariasis & Chronic Obs. Pulmonary Dis. \\
Malaria & Bronchogenic Carcinoma \\
SEMESTER II & \\
Cardio-vascular & \\
System & \\
Hypertension & Ischaemic Heart Disease \\
Rheumatic Fever & Rheumatic Heart Disease \\
\hline
\end{tabular}

\begin{tabular}{|ll|}
\hline SEMESTER III & \\
\hline $\begin{array}{l}\text { Gastro-Intestinal } \\
\text { System }\end{array}$ & Renal \& Electrolyte \\
Worm Infestation & System \\
Acid Peptic Disease & Glomerulo-Nephritis \\
Diarrhoea & Nephrotic Syndrome \\
Dysentery & Urinary Calculi \\
Constipation & Haematuria \\
Colitis & Albuminuria \\
& Renal Failure \\
\hline
\end{tabular}

\begin{tabular}{|l|c|}
\hline SEMESTER IV & Central Nervous \\
Reproductive System & Sinusitis \\
$\begin{array}{l}\text { Pregnancy - Normal \& } \\
\text { Abnormal } \\
\text { Sexually Transmitted } \\
\text { Diseases }\end{array}$ & Meningitis \\
Acquired Immuno Deficiency & Epilepsy \\
Syndrome (AIDS) & Cerebro \\
Cancer Cervix & Vascular \\
& Accident \\
Pelvic Inflammatory & Encephalitis \\
Diseases & Poliomyelitis \\
& Cataract \\
& Deafness \\
& Migrane \\
\hline
\end{tabular}

N.B. Total number of common conditions listed in the KU curriculum:

First year - Twenty- one in first semester and fourteen in second. Total -35

Second year - Seventeen in third semester and fourteen in fourth. Total -31

\section{REFERENCES}

1. Pant DS. Experiences from the Institute of Medicine, Tribhuvan University on introducing Problem Based Learning (PBL) in an organ system based integrated curriculum. J Nepal Med Assoc. 2000; 39:232-39.
2. Mansur DI, Kayastha SR, Makaju R, Dongol M. Problem Based Learning in Medical Education. Kathmandu Univ Med J (KUMJ). 2012 Oct-Dec;10(40):78-82.

3. Pradhan B, Ranjit E, Ghimire MR, Dixit H. History of Problem Based Learning in Nepal and experiences at 
Kathmandu Medical Colleges. 2012;1(1):37-44.

4. Pre Clinical Sciences revised version of MBBS Curriculum of Kathmandu University School of Medical Sciences (KUSMS).

5. Barrows HS \& Tamblyn RM. Problem Based Learning. An Approach to Medical Education, 1980, Springer Publishing Company New York.

6. Problem based learning at HYMS - A Guide for Students by Students. 2004-2005.

7. Papinzak T, Young L, Graves M. Peer Assessment in Problem Based Learning: A Qualitative Study. Advances in Health Sciences Education. 2007;12:169-186.

8. Preparing Working Problems for an Integrated Problem Based Curriculum. McPherson J * Murphy P in Curriculum Delivery, 180-191.
9. Jayawickramrajah PT. Problems for problem based learning: a comparative study of documents. Medical Education. 1996; 30:272-282

10. Report of PBL Workshop -1 at Nepal Medical College, Feb. 2013.

11. Lama PY et al. Integration of Problem Based Learning at Kathmandu Medical College. Journal of Kathmandu Medical College. 2013;2(3):162-166.

12. Butler R, Inman D, Lobb D, Problem-based learning and the medical school; another case of the emperor's new clothes? Adv Physiology Educ. 2005;29(4):194-6.

13. Savery JR. Overview of Problem Based Learning: Definitions and Distinctions. Interdisciplinary Journal of Problem-based Learning. 2006. Published Online. 